\title{
FLEXURAL-GRAVITY WAVES ON FLOATING STRATIFIED ICE
}

\author{
By Edwin S. Robinson \\ (Department of Geological Sciences, Virginia Polytechnic Institute and State University, \\ Blacksburg, Virginia 24061, U.S.A.)
}

\begin{abstract}
A BSTRACT. Flexural-gravity waves in the $3 \mathrm{~ms}$ to $50 \mathrm{~ms}$ period range were recorded on floating layers of ice ranging from $6 \mathrm{~cm}$ to $52 \mathrm{~cm}$ in thickness. These inversely dispersive waves are analogous to Rayleigh waves propagating on a multi-layered structure. Therefore. flexural-gravity wave dispersion curves can be calculated by the well-known Haskell--Thompson method. This approach allows the effects of snow layers and stratification of the ice to be evaluated. In earlier methods of calculating flexural-gravity wave dispersion. the structure was restricted to a single homogeneous solid layer over a homogeneous fluid. The effect of a low-velocity snow layer is to reduce the short-period phase velocity, and to increase the velocity at long periods. Dispersion curves for ice layers with and without a snow cover cross at an intermediate period that increases as ice thickness increases. These effects are measurable in seismic experiments on frozen ponds and lakes.
\end{abstract}

RÉsumé. Ondes de flexion dans la glace flottante stratifiee. On a enregistrè des ondes de flexions dans une gamme de période de 3 à $50 \mathrm{~ms}$ sur des glaces flottantes de 6 à $52 \mathrm{~cm}$ d’épaisseur. Ces ondes à dispersion inverse sont analogues à des ondes de Rayleigh se propageant dans un milieu à plusieurs couches. Dès lors les courbes de dispersion des ondes de flexion peuvent être calculées par la méthode bien connue de Haskell-Thomson. Cette approche permet d'estimer les effets de la présence de couches de neige et de la stratification de la glace. Dans les plus récentes méthodes de calcul de la dispersion des ondes de flexion la structure a été réduite à une seule couche solide homogène sur un fluide homogène. L'effet d'une couche de neige à faible vitesse est de réduire la vitesse des phases á courtes périodes et d'accroitre cette vitesse pour les longues périodes. Les courbes de dispersion pour des niveaux de glace avec et sans couche de neige se croisent pour une période intermédiaire qui croît quand l'épaisseur de la glace augmente. Ces effets sont mesurables dans des expériences sismiques sur des ètangs et des lacs gelés.

ZuSAmmenfassung. Beugungswellen in schurmmendem geschichtetem Eis. Beugungswellen mit Perioden von 0.003 bis $0.050 \mathrm{~s}$ wurden an schwimmenden Eisplatten von 6-52 cm Dicke aufgezeichnet. Diese inversen Streuungswellen sind analog den Rayleigh-Wellen, die sich an einer mehrschichtigen Struktur fortpflanzen. Deshalb können Streuungskurven der Beugungswellen mit der allgemein bekannten Haskell-Thompson-Methode berechnet werden. Diese Methode erlaubt es, den Einfluss der Schneeschichten und der Eisschichten Abzuschätzen. Frühere Methoden erlaubten nur die Analyse von Strukturen, die aus einer homogenen festen Schicht über einer homogenen Flüssigkeit bestanden. Die niedere Fortpflanzungsgeschwindigkeit in den Schneeschichten bewirkt eine Abnahme der Phasengeschwindigkeit für Kurzperioden und eine Zunahme für Langperioden. Streuungskurven für Eisplatten mit und ohne Schneedecke kreuzen sich bei einer Mittelperiode, die mit der Dicke der Eisschicht zunimmt. Diese Effekte sind experimentell mittels seismischer Methoden an gefrorenen Teichen und Seen messbar.

\section{INTRODUCTION}

Flexural-gravity waves on floating ice sheets are inversely dispersive Rayleigh-type surface waves. They are useful for in-situ measurements of the physical properties of the ice. The propagation of these waves on frozen lakes has been studied by Ewing and Crary (1934), Press and others (1951), and Taylor (1979). They observed flexural-gravity waves with periods shorter than $1 \mathrm{~s}$ that were generated by impulsive sources on ice less than $1 \mathrm{~m}$ thick. Similar observations on sea ice up to $3 \mathrm{~m}$ thick have been reported by Oliver and others (1954), and Hunkins (1960). Crary (1954) described impulse-generated flexural-gravity waves at periods between $0.04 \mathrm{~s}$ and $4 \mathrm{~s}$ on the $60 \mathrm{~m}$ thick floating ice island T-3. Flexural-gravity waves at periods from $15 \mathrm{~s}$ to $1 \mathrm{~min}$ were recorded by Hunkins (1962) on the ice-covered Arctic Ocean. 
Williams and Robinson (1981) measured flexural-gravity waves on the Ross Ice Shelf at periods between 2 min and 15 min that were generated by ocean swell in the northern Ross Sea.

In all of these studies measured flexural-gravity wave dispersion was compared with dispersion curves obtained from the period equation of Ewing and Crary (1934) or from the period equation of Press and Ewing (1951). Both of these equations relate the wavelength dependent phase velocity to the thickness and elasticity of a homogeneous solid plate resting on a fluid. But in Nature floating ice sheets tend to become stratified. On frozen lakes and seas layers build up from repeated snowfall, brief thaws, and rainfall, followed by freezing and recrystallization in the mixture of water and snow. Depth-dependent elasticity in thicker ice islands and ice shelves evolves from firn compaction and recrystallization. Elasticity variation with depth in ice sheets is also related to vertical temperature gradients.

In theory flexural-gravity waves are constrained by the same boundary conditions of stress and displacement that must be satisfied by Rayleigh waves in a plane layered half-space. Therefore, the period equation derived by Haskell (1953) describes flexural-gravity wave dispersion on a stratified floating ice sheet. After modifying this theory to accept liquid layers more efficiently, Dorman (1962) suggested that it be used to study surface-wave propagation on floating ice. Dispersion curves obtained from this modified theory illustrate the sensitivity of flexural-gravity waves to laminations in ice.

\section{THEORY}

The period equation of Ewing and Crary (1934) expresses the wavelength- $(\lambda)$-dependent phase velocity $C$ of flexural-gravity waves on a thin plate resting on a fluid as

$$
C^{2}=\frac{(g \lambda / 2 \pi)+\left(8 \pi^{3} D / \rho_{\mathrm{w}} \lambda^{3}\right)}{\left(2 \pi \rho_{\mathrm{i}} h_{\mathrm{i}} / \rho_{\mathrm{w}} \lambda\right)+(1 / q) \operatorname{coth}\left(2 \pi q h_{\mathrm{w}} / \lambda\right)}
$$

where the plate is described by thickness $h_{\mathrm{i}}$, density $\rho_{\mathrm{i}}$, and flexural rigidity $D$, the fluid is described by thickness $h_{\mathrm{w}}$ and density $\rho_{\mathrm{w}}$, and the factor $q=\left[1-\left(C^{2} / \alpha_{\mathrm{w}}^{2}\right)\right]^{1 / 2}$ depends on the velocity $\alpha_{w}$ of a compressional wave in the fluid. This equation, which accounts for compressibility of the fluid, is a modification of the earlier equation of Greenhill (1887) in which the fluid is considered incompressible.

The period equation of Haskell (1953) cannot be expressed concisely in a form that displays all of the relevant parameters. This equation is for a multi-layered solid structure where elastic waves produce stresses and displacements at the top and bottom of each layer that can be related to its elastic properties by a $4 \times 4$ matrix. Conditions for continuity of stress and displacement across layer boundaries are satisfied by the product of the layer matrices which is a single $4 \times 4$ matrix $J$ expressing the elastic response of the structure. The conditions that stress vanish at the free surface and that no sources exist at infinite depth require the period equation of Haskell (1953):

$$
\left(J_{22}-J_{12}\right)\left(J_{31}-J_{41}\right)=\left(J_{42}-J_{32}\right)\left(J_{11}-J_{21}\right)
$$

where the matrix elements $J_{j k}$ are functions of phase velocity, wavelength, thickness, density, and the elastic parameters of each layer in the structure. The method for obtaining $J$ was modified by Dorman (1962) to accept efficiently structures with both solid and fluid layers. The flexural wave period equation of Press and Ewing (1951) can be obtained from this modified formulation for 
the special case where a solid layer in which Poisson's Ratio equals $1 / 4$ rests on a semi-infinite fluid.

Compressional $(\alpha)$ and shear $(\beta)$ wave velocities can represent the elastic parameters in Equation (1) where $D=\rho \beta^{2} h^{3}\left(\alpha^{2}-\beta^{2}\right) / 3 \alpha^{2}$, and in Equation (2) where they are used to calculate numerical coefficients for the combinations of $C$ and $\lambda$ occurring in the elements of layer matrices prior to obtaining $J$. The equations can be solved by iteration using trial values of $C$ for a fixed value of $\lambda$. The corresponding period $T=\lambda C$ can then be found.

\section{OBSERVATIONS}

Frozen ponds and lakes in western Virginia provided sites for flexural-gravity wave measurements on both homogeneous and horizontally stratified plates of floating ice. Flexural-gravity waves produced by striking the ice with a hammer were recorded on arrays of

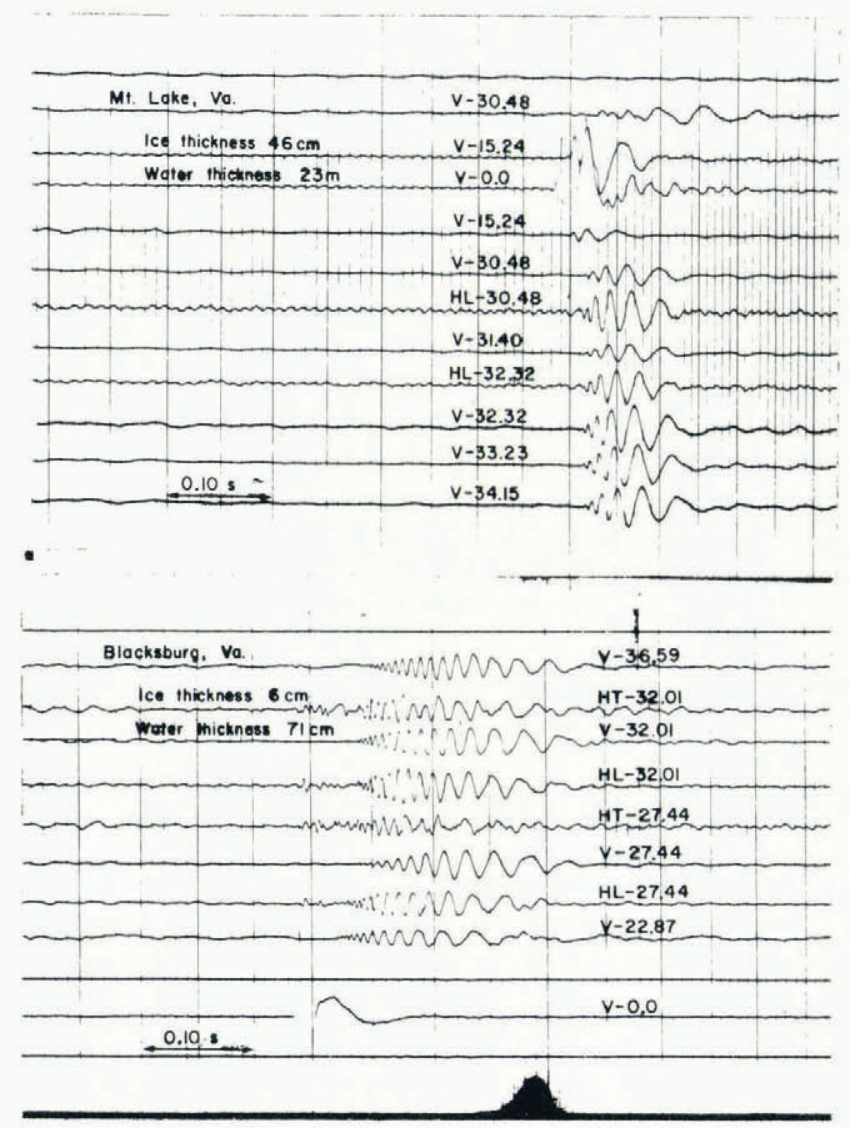

Fig. 1. Seismograms displaying flexural waves recorded on Mountain Lake in Giles County, Virginia, and a pond in Blacksburg, Virginia. Distances (meters) and seismometer orientations (V-vertical, HL-horizontal longitudinal, HT-horizontal transverse) are indicated on individual traces. Amplification is different on different traces. 
vertical and horizontal seismometers at $0.6 \mathrm{~m}, 0.9 \mathrm{~m}$, or $4.6 \mathrm{~m}$ intervals using an ElectroTechnical Laboratories 12 channel analog seismic system. The arrays consisted of four to twelve seismometers in line with source points at distances between $15 \mathrm{~m}$ and $65 \mathrm{~m}$. Representative seismograms are reproduced in Figure 1.

Particle-motion diagrams (Fig. 2) prepared from these seismograms display retrograde elliptical movement typical of Rayleigh-type surface waves. Inclination from vertical of the major axis of the ellipse is expected for Rayleigh-wave propagation on an anisotropic medium (Crampin, 1977) such as ice.

Flexural-gravity wave dispersion data from four representative sites are displayed in Figures $3,4,5$, and 6 . Points indicate phase velocities and periods obtained from arrival times of aligned peaks and troughs on the seismograms. This is an inexact method for determining dispersion because phases in the wave group change over the finite length of the seismometer array (Jeffreys and Jeffreys, 1956). More exact methods involving spectral analysis were judged impractical for the analog seismograms used in this study. Error caused by phase changes along the $2 \mathrm{~m}$ to $6 \mathrm{~m}$ seismometer arrays can be estimated by superposing the waveforms used to obtain a particular phase velocity-period point. Waveform differences indicate that systematic changes of as much as $0.0005 \mathrm{~s}$ at periods of approximately $0.07 \mathrm{~s}$ decrease for shorter periods, and are indiscernible at periods shorter than $0.01 \mathrm{~s}$. This implies that no point displayed in Figs 3, 4, 5, and 6 should
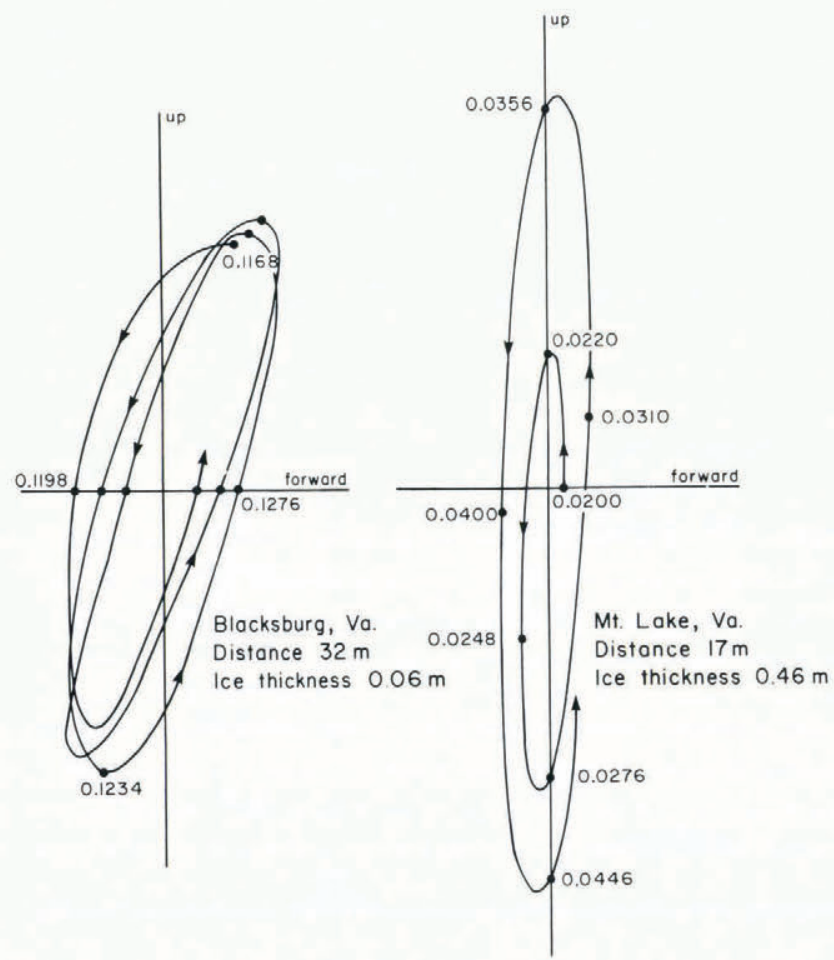

Fig. 2. Particle-motion diagrams prepared from portions of seismograms recorded at Blacksburg and Mount Lake. Distance from source (meters), and ice thickness (meters) are indicated for each diagram. Numbers on the diagrams give time (seconds) at selected points. Vertical and horizontal scales are in arbitrary linear units. 

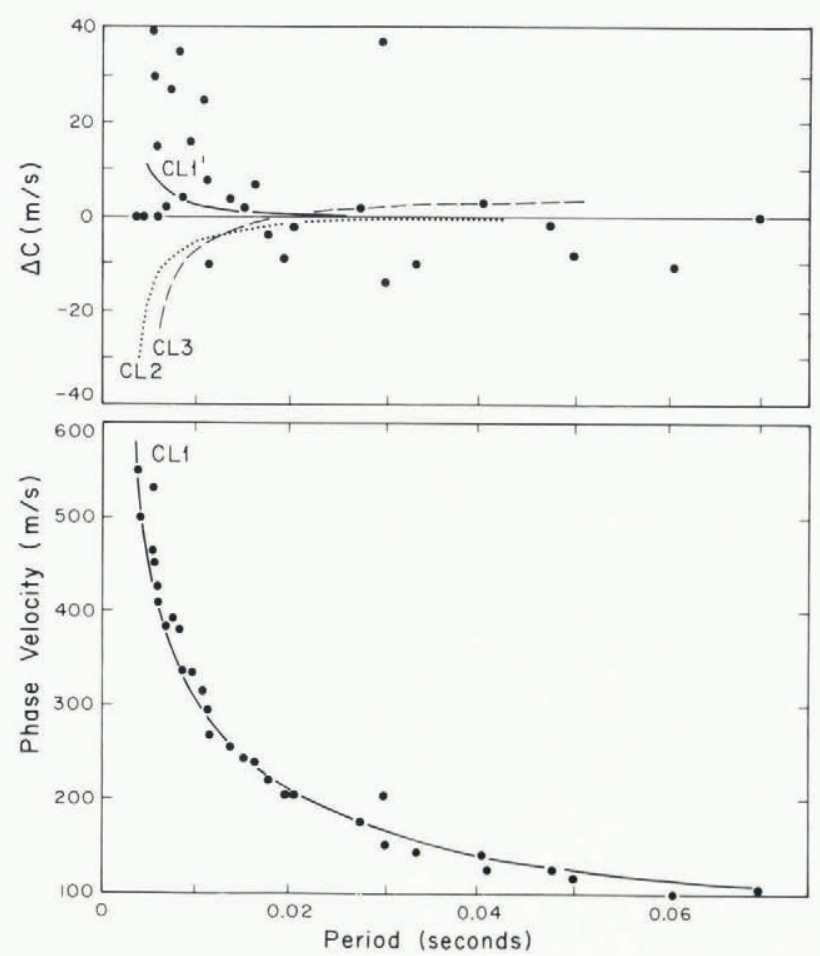

Fig. 3. Flexural-wave phase-velocity dispersion at a site on Claytor Lake, Virginia. Lower diagram compares measured points with curve computed for Model CLI using Equation (2). Upper diagram shows departures from the curve CLI of measured values, dispersion curves computed for Models CL2 and CL3 using Equation (2) and a dispersion curve CLI' computed for Model CLI using Equation (1).

be in error by more than its radius as a result of changes in the wave group along the seismometer array.

Dispersion curves in Figures 3, 4, 5, and 6 were prepared from solutions to Equations (1) and (2) using physical properties from Table I and layer thicknesses from Table II. The FORTRAN program used for the computations is a modification of the one described by Dorman and others (1960). At each site ice thickness, water thickness, and the thicknesses of recognizable ice and snow laminations were measured at $2 \mathrm{~m}$ to $3 \mathrm{~m}$ intervals along the seismometer arrays. Ice thickness was found to be remarkably uniform. Variations were smaller than $0.5 \mathrm{~cm}$. The dependence of phase velocity on ice thickness, determined from solutions to Equations (1) and (2) using different trial values of $h_{\mathrm{i}}$, indicates that such small variations would have a negligible effect on the positions of the dispersion curves in Figures 3, 4, 5, and 6.

Specimens for laboratory measurements of physical properties were obtained from a $30 \mathrm{~cm}$ thick layer of stratified ice covering the pond in Blacksburg, Virginia. For six specimens of clear ice containing small and sparsely distributed air bubbles, values of $\alpha$ (vertical $)=3944 \pm 33 \mathrm{~m} / \mathrm{s}$, $\alpha($ horizontal $)=3846 \pm 31 \mathrm{~m} / \mathrm{s}$, and $\rho_{\mathrm{i}}=0.91 \mathrm{Mg} / \mathrm{m}^{3}$ were obtained, where limits of uncertainty are standard deviations from the mean. For eleven specimens of porous ice, measured values ranged from $\alpha=3737 \mathrm{~m} / \mathrm{s}$ where $\rho_{\mathrm{i}}=0.87 \mathrm{Mg} / \mathrm{m}^{3}$ to $\alpha=3849 \mathrm{~m} / \mathrm{s}$ where $\rho_{\mathrm{i}}=0.89 \mathrm{Mg} / \mathrm{m}^{3}$. No significant differences between horizontal and vertical velocities were detected. The visual 

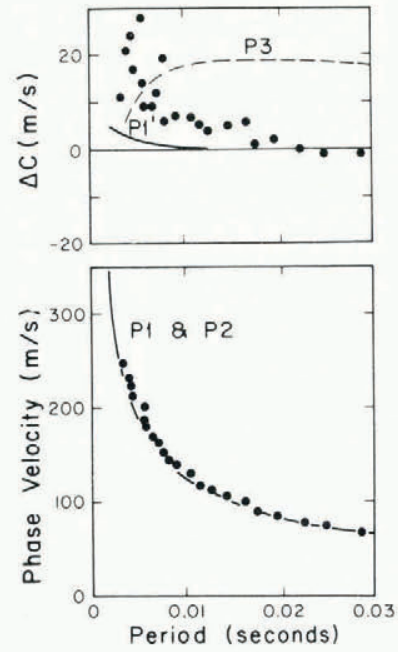

Fig. 4. Flexural-wave phase-velocity dispersion at a site on a pond in Blacksburg, Virginia where ice thickness was $6 \mathrm{~cm}$. Lower diagram compares measured points with curve computed for Model P1 using Equation (2). Upper diagram shows departures from the curve P1 of measured values, $a$ dispersion curve P1' computed for Model P1 using Equation (1), and a dispersion curve computed for Model P3 using Equation (2).
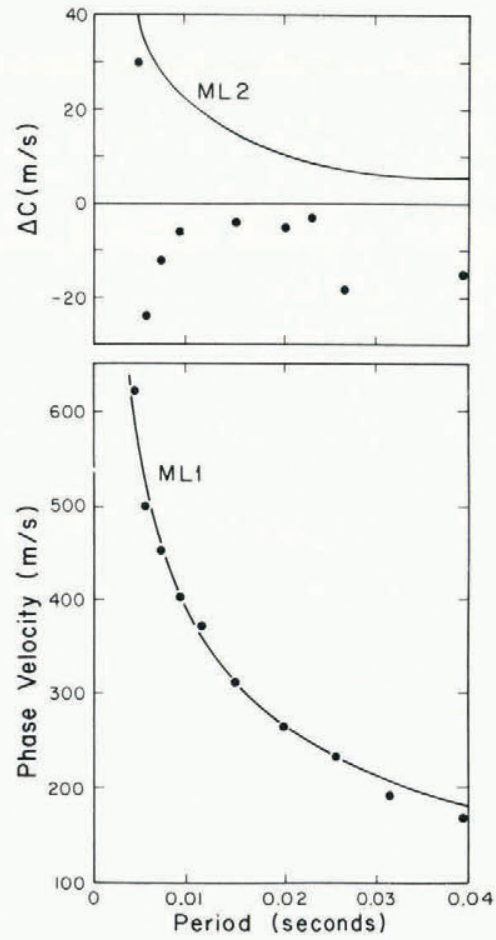

Fig. 5. Flexural-wave phase-velocity dispersion at a site on Mountain Lake, Virginia. Lower diagram compares measured points with curve computed for Model MLI using Equation (2). Upper diagram shows departures from the curve $M L 1$ of measured values, and a dispersion curve computed for Model ML2 using Equation (2).

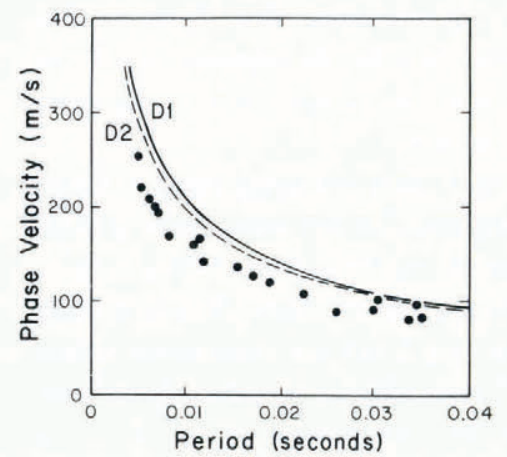

Fig. 6. Flexural-wave phase-velocity dispersion at a site on a pond in Blacksburg, Virginia where a layer of ice $14 \mathrm{~cm}$ thick was covered by $3 \mathrm{~cm}$ of slush and $10 \mathrm{~cm}$ of snow. Measured points are compared with dispersion curves computed for Models D1 and D2 using Equation (2). 
TABLE I. MATERIAL PARAMETERS

\begin{tabular}{clrrc} 
Symbol & \multicolumn{1}{c}{ Material } & $\begin{array}{c}\alpha \\
\mathrm{m} \mathrm{s}^{-1}\end{array}$ & $\begin{array}{c}\beta \\
\mathrm{m} \mathrm{s}^{-1}\end{array}$ & $\begin{array}{c}\rho \\
\mathrm{Mg} \mathrm{m}^{-3}\end{array}$ \\
I1 & Ice-clear, non-porous & 3900 & 1950 & 0.910 \\
I2 & Ice-clear, porous & 3840 & 1875 & 0.905 \\
I3 & Ice-gray, porous & 3720 & 1775 & 0.885 \\
I4 & Ice-white, porous & 3650 & 1675 & 0.870 \\
S1 & Snow-dry, recrystallized & 1600 & 1000 & 0.50 \\
S2 & Snow-dry, packed & 500 & 260 & 0.40 \\
S3 & Snow-water-saturated & 1500 & 0 & 0.98 \\
W1 & Water & 1400 & 0 & 1.00 \\
C1 & Sediment & 2000 & 1150 & 2.00 \\
R1 & Rock & 6000 & 3600 & 2.67
\end{tabular}

appearance of these specimens was compared with the appearance of stratified ice at the other locations where logistical difficulties precluded in situ or laboratory measurements of physical properties. These comparisons together with velocity and density data presented by Röthlisberger (1972) guided the choice of values in Table I. Because of the subjectivity in selection of $\mathrm{P}$-wave and $\mathrm{S}$-wave velocities for porous ice layers, values given in Table I were changed by $\pm 50 \mathrm{~m} / \mathrm{s}$ in trial calculations to ascertain effects on positions of the dispersion curves. Phase velocities were changed by less than $\pm 10 \mathrm{~m} / \mathrm{s}$ at a period of $0.004 \mathrm{~s}$ and less than $\pm 2 \mathrm{~m} / \mathrm{s}$ at a period of $0.04 \mathrm{~s}$. These changes are too small to alter the conclusions of this study.

\section{Discussion}

Results from a site on Claytor Lake are presented in Figure 3. The $28 \mathrm{~cm}$ ice layer containing sparsely-scattered air bubbles had formed by basal freezing without alteration of its upper surface by precipitation or melting. Points in Figure 3 that indicate measured dispersion of phase velocity show a small but systematic departure from the curves CL1 and CL1' that predict dispersion on a homogeneous, isotropic, and perfectly elastic plate. Curve CL1 was obtained from Equation (2), and curve CL1' was obtained from Equation (1). At short periods measured

\section{TABLE II. MODEL LAYER THICKNESSES $(\mathrm{cm})$}

\begin{tabular}{cccrrrrrrr}
\multicolumn{2}{c}{ Model CLI } & \multicolumn{2}{c}{ Model P1 } & \multicolumn{2}{c}{ Model MLI } & \multicolumn{2}{c}{ Model D1 } & \multicolumn{2}{c}{ Model CL2 } \\
I1 & 28 & I1 & 6 & S1 & 6 & I1 & 14 & S2 & 30 \\
W1 & 520 & W1 & 71 & I4 & 8 & W1 & 100 & I1 & 28 \\
R1 & $\infty$ & C1 & $\infty$ & I3 & 8 & C1 & $\infty$ & W1 & 520 \\
& & & & I2 & 30 & & & R1 & $\infty$ \\
& & & & W1 & 2300 & & & & \\
& & & & R1 & $\infty$ & & &
\end{tabular}

\begin{tabular}{rrrrrrrrrrr}
\multicolumn{2}{c}{ Model $P 2$} & \multicolumn{2}{c}{ Model ML2 } & \multicolumn{2}{c}{ Model D2 } & \multicolumn{2}{c}{ Model CL3 } & \multicolumn{2}{c}{ Model P3 } \\
I1 & 6 & I1 & 46 & S2 & 20 & S2 & 60 & S2 & 30 \\
W1 & 71 & W1 & 2300 & S3 & 3 & I1 & 28 & I1 & 6 \\
R1 & $\infty$ & R1 & $\infty$ & I1 & 14 & W1 & 520 & W1 & 71 \\
& & & & W1 & 100 & R1 & $\infty$ & C1 & $\infty$
\end{tabular}


phase velocity appears to be slightly higher, and at long periods it appears to be slightly lower than the predicted velocity. This systematic departure may be related to anisotropy (Crampin. 1977) which is indicated by inclined axes of particle-motion ellipses in Figure 2. At this site the water thickness $(5.2 \mathrm{~m})$ was sufficiently larger than the half-wavelength $(3.5 \mathrm{~m})$ of the longest recorded phase for rock or sediment beneath the water to have negligible effect on the phase velocity.

The departure of curve $\mathrm{CLl}^{\prime}$ from curve $\mathrm{CLl}$ at short periods indicates the error related to the assumption used in the derivation of Equation (1) that plate thickness is small relative to wavelength. Curves CL2 and CL3 illustrate how the addition of packed snow layers $30 \mathrm{~cm}$ and $60 \mathrm{~cm}$ thick would alter the dispersion of flexural-gravity waves. Except at short periods, the effects of such snow layers would be difficult to detect by the experimental techniques used in this study.

Phase velocity dispersion data from a pond in Blacksburg, Virginia, are presented in Figure 4. Here a water layer only $71 \mathrm{~cm}$ thick was covered by a homogeneous ice plate $6 \mathrm{~cm}$ thick. Measured phase velocity was slightly higher at short periods, and slightly lower at long periods than the velocity predicted in curves $\mathrm{P} 1, \mathrm{P}^{\prime}$, and $\mathrm{P} 2$. Again, this small departure may be related to anisotropy in the ice. At short periods curve P1', obtained from Equation (1), departs from curve Pl, obtained from Equation (2), because of the previously mentioned thin-plate assumption.

The dispersion curves for models P1 and P2 are identical even though properties of the sediment layer in the former are quite different from the properties of the rock layer in the latter. These results indicate that dispersion is not affected by material beneath a thin water layer even at long wavelengths. The dispersion curve P3 illustrates that the change in phase velocity produced by adding a snow layer $30 \mathrm{~cm}$ thick could be detected by the experimental techniques used in this study.

Phase-velocity dispersion on a horizontally stratified ice plate was measured at a site on Mountain Lake. Model ML1 represents the structure of the ice plate which consisted of a basal layer of bubbly ice formed by freezing on the bottom, and three distinct layers that were produced by repeated cycles of snow, rain, and thaw, followed by freezing and recrystallization of the mixture of water and ice grains. Points in Figure 5 representing measured phase velocity are close to the velocity predicted by the dispersion curve of Model ML1. Measured phasevelocity dispersion is clearly different from the dispersion predicted by curve ML2 for homogeneous ice, which indicates that effects of stratification can be detected.

Measurements were repeated on the pond in Blacksburg after ice thickness had increased to $14 \mathrm{~cm}$, and alternating rain and snow at temperatures close to freezing had produced a $3 \mathrm{~cm}$ thick slush mixture of water and ice grains covered by $10 \mathrm{~cm}$ of snow. Points in Figure 6 indicate that measured phase velocity is markedly lower than the velocity predicted by curve DI for a homogeneous ice plate. The curve D2 predicts that the addition of slush and snow layers would reduce phase velocity, but not to the extent that was observed. Clearly, these surface layers have an important effect on flexural-gravity wave dispersion.

\section{ACKNOWLEDGEMENTS}

Field experiments were done with the assistance of J. L. Wonderley, R. W. Montgomery, 
R. T. Williams, and H. A. C. Neuburg. Facilities of the Computing Center of Virginia Polytechnic Institute and State University were made available for this study.

MS. received 11 November 1981 and in revised form 7 May 1982

\section{REFERENCES}

Crampin. S. 1977. A review of the effects of anisotropic layering on the propagation of seismic waves. Geophysical Journal. Royal Astronomical Society, Vol. 19, No. 1, p. 9-27.

Crary. A. P. 1954. Seismic studies on Fletcher's ice island, T-3. Transactions, American Geophysical Union, Vol. 35. No. 2, p. 293-300.

Dorman, J. 1962. Period equation for waves of Rayleigh type on a layered, liquid-solid half space. Bulletin of the Seismological Society of America, Vol. 52, No. 2, p. 389-97.

Dorman. J., and others. 1960. Study of shear velocity distribution in the upper mantle by mantle Rayleigh waves, by J. Dorman, [W.| M. Ewing, and J. Oliver. Bulletin of the Seismological Society of America, Vol. 50. No. 1. p. $87-115$.

Ewing, W. M., and Crary, A. P. 1934. Propagation of elastic waves in ice. Pt. II. Physics, Vol. 5, No. 7. p. $181-84$.

Greenhill, A. G. 1887. Wave motion in hydrodynamics. American Journal of Mathematics, Vol. 9. No. 1, p. $62-112$.

Haskell. N. A. 1953. The dispersion of surface waves on multilayered media. Bulletin of the Seismological Society of America, Vol. 43, No. 1, p. 17-34.

Hunkins, K. 1960. Seismic studies of sea ice. Journal of Geophysical Research, Vol. 65, No. 10, p. 3459-72.

Hunkins, K. 1962. Waves on the Arctic Ocean. Journal of Geophysical Research, Vol. 67. No. 6. p. $2477-97$.

Jeffreys. H., and Jeffreys. B. S. 1956. Methods of mathematical physics. Third edition. Cambridge, Cambridge University Press.

Oliver, J.. and others. 1954. Elastic waves in Arctic pack ice, |by| J. Oliver, A. P. Crary, and R. Cotell. Transactions, American Geophysical Union, Vol. 35. No. 2, p. 282-92.

Press. F., and Ewing, W. M. 1951. Propagation of elastic waves in a floating ice sheet, Transactions, American Geophysical Union, Vol. 32, No. 5, p. 673-78.

Press, F., and others. 1951. Air-coupled flexural waves in floating ice, [by] F. Press, A. P. Crary, J. Oliver, and S. Katz. Transactions, American Geophysical Union, Vol. 32, No. 2, p. 167-72.

Röthlisberger, H. 1972. Seismic exploration in cold regions. Hanover, N. H., U.S. Cold Regions Research and Engineering Laboratory. (Cold Regions Science and Engineering Monograph II-A2a.)

Taylor. R. W. 1979. Flexural wave studies on the basis of single-sensor recordings. Journal of Glaciology, Vol. 22. No. 86, p. 171-75.

Williams. R. T., and Robinson, E. S. 1981. Flexural waves in the Ross Ice Shelf. Journal of Geophysical Research, Vol. 86. No. C7, p. 6643-48. 